\title{
Changes in Antibiotic Resistance of Acute Bacterial Prostatitis in a Korean Single Center
}

\author{
Byoung Hoon Kim, Kwibok Choi, In-Chang Cho, Seung Ki Min \\ Department of Urology, National Police Hospital, Seoul, Korea
}

\begin{abstract}
Purpose: Acute bacterial prostatitis (ABP) is one of main infective disease in urology with various symptoms. Occurrence of complications can be minimized by appropriate treatment. We studied whether any changes in antimicrobial resistance of hospitalized ABP patients as time passed.
\end{abstract}

Materials and Methods: The study was based on retrospective study. From 2004 to 2007 as past period and 2014 to 2017 as recent period defined. Patient's ages, length of admission days, intensive care, urinalysis, strains, and resistance to antibiotics were investigated in hospitalized patients with ABP and compared between the two periods.

Results: Fifty patients of past period and 72 patients of recent period with $A B P$ were admitted. The mean age was increased $55.5 \pm 13.2$ years to $62.0 \pm 15.3$ years. The infection route was mostly community-acquired. Prostate biopsy-related was decreased 7 to 1 . The mean of hospital days were $7.9 \pm 4.2$ days to $6.9 \pm 3.4$ days. Intensive care were 5 to 7 . Average length of stay intensive care was $4.2 \pm 1.3$ days to $4.1 \pm 1.4$ days. Urine cultures showed no significant difference from the previous studies in strains. Extended spectrum beta-lactamases producing bacteria increased $4.3 \%$ to $25.0 \%$, and third generation cephalosporin resistance was increased $13.0 \%$ to $40.9 \%$. Fluoroquinolone was no significant change $26.1 \%$ to $27.3 \%$. Aminoglycosides were identified in $4.3 \%$ to $6.8 \%$ and carbapenem in $4.3 \%$ to $2.3 \%$.

Conclusions: The mean age of hospitalized patients with ABP increased. Antimicrobial resistance did not change to fluoroquinolone, but extended spectrum beta-lactamases producing bacteria showed increased resistance to third-generation cephalosporin. Therefore, attention should be paid to the use of empirical antibiotics.

Keywords: Bacterial infection; Prostatitis; Anti-bacterial agent; Bacterial drug resistance

Copyright (c) 2019, Korean Association of Urogenital Tract Infection and Inflammation. All rights reserved. (C) (1) (s) This is an open access article distributed under the terms of the Creative Commons Attribution Non-Commercial License (http://creativecommons.org/licenses/by-nc/4.0) which permits unrestricted non-commercial use, distribution, and reproduction in any medium, provided the original work is properly cited.
Received: 16 November, 2018

Revised: 29 March, 2019

Accepted: 10 April, 2019

\author{
Correspondence to: Seung Ki Min \\ (iD) https://orcid.org/0000-0002-9638-9668 \\ Department of Urology, National Police Hospital, \\ 123 Songi-ro, Songpa-gu, Seoul 05715, Korea \\ Tel: +82-2-3400-1264, Fax: +82-2-431-3192 \\ E-mail: drmsk@korea.com
}

\section{INTRODUCTION}

Acute bacterial prostatitis is one of the main infectious diseases studied in urology and can occur in people of any age. The symptoms can vary, such as bladder irritation caused by urinary tract infections (dysuria, urinary frequency and urgency), symptoms caused by inflammation of the prostate (perineal, genital, back and rectal pain), and 
symptoms due to bacteremia (fever, chills, and arthralgia). Complications can occur in the course of treatment, such as chronic bacterial prostatitis, epididymitis, prostate abscess, sepsis, chronic pelvic pain syndrome, etc. The occurrence of complications can be minimized by proper empirical treatment $[1,2]$.

No large-scale meta-analysis or control study of acute bacterial prostatitis has been performed despite the high importance of empirical antibiotics in early treatment [3-6]. A review of previous studies and other guidelines has recommended the early use of empirical antibiotics for acute bacterial prostatitis and admission to hospital [2,7]. This study examined the antibiotic resistance of patients with acute bacterial prostatitis and compared the clinical features of the patients with the past and present.

\section{MATERIALS AND METHODS}

The study was based on a retrospective case study (medical records) of patients admitted to the National Police Hospital. Patients from 2004 to 2007 and from 2014 to 2017 were classified as the past and recent period, respectively. The clinical characteristics, such as age, infection route, hospital stay, intensive care unit admission, and antibiotic resistance by urine cultures, of the patients treated with acute bacterial prostatitis were examined. This study was approved by the institutional review board of National Police Hospital (No. 11100176-201810-HR-007) and the requirement for written informed consent was waived. The differences between the two periods were compared with respect to these clinical characteristics. A t-test and chisquare crossover analysis according to the variables were performed to determine the significance of the differences. p-values $<0.05$ were considered significant. The statistical program used was IBM PASW Statistics ver. 18 (IBM Corp., Armonk, NY, USA).

\section{RESULTS}

Fifty patients in the past period and 72 patients in the recent period with acute bacterial prostatitis were admitted to the authors' hospital. The mean age of the patients increased from $55.5 \pm 13.2$ years in the past period to $62.0 \pm 15.3$ years in the recent period $(p=0.016)$. Twelve patients $(24.0 \%)$ in the past period and 26 patients $(36.1 \%)$ in the recent period were diagnosed with hypertension. Four patients $(8.0 \%)$ in the past period and 12 patients $(16.7 \%)$ in the recent period were diagnosed with diabetic mellitus. Two patients (4.0\%) in the past period and five patients $(6.9 \%)$ in the recent period had a history of cerebrovascular accidents. The infection route was found to be a community infection in 42 cases (84.0\%) in the past period and 67 cases (93.1\%) in the recent period. The number of post prostate biopsy was decreased from $7(14.0 \%)$ cases in past period to 1 case $(1.4 \%)$ in recent period $(\mathrm{p}=0.008)$. Regarding urologic manipulation except for a prostate biopsy, one case occurred after cystoscopy the in past period and one case after a transurethral resection of the prostate in the recent period. The number of hospital days decreased from 7.9 \pm 4.2 days in the past period to $6.9 \pm 3.4$ days in the recent period, but the difference was insignificant. Patients entering the intensive care unit were five cases in the past period and seven cases in the recent period. The mean duration of intensive care unit stay-days was $4.2 \pm 1.3$ days in the past period and $4.1 \pm 1.4$ days in the recent period, showing no significant difference (Table 1).

A total of 67 cases were identified from the urine cultures: 23 cases in the past period and 44 cases in the recent period. Bacteria were not identified in 27 cases in the past period and 28 cases in the recent period. When only urine cultures were identified in the past period, Escherichia coli was the most common microorganism in 18 cases $(78.3 \%)$, followed in order by three cases (13.0\%) of Klebsiella pneumoniae, one case (4.3\%) of Pseudomonas aeruginosa and one case $(4.3 \%)$ of Enterococcus. In the latter cases, E. coli was the most common in 26 cases (59.1\%), followed in order by $K$. pneumoniae in four cases $(9.1 \%), P$. aeruginosa in two cases $(4.5 \%)$ and Enterococcus in three cases (6.8\%). As other species, Proteus mirabilis, Staphylococcus aureus, and Streptococcus were identified in nine cases $(20.5 \%)$.

In the case of antibiotic resistance, the positive extendedspectrum beta lactamases (ESBL) producing bacteria increased from $4.3 \%$ in the past period to $25.0 \%$ in the recent period $(p=0.045)$, and the resistance to third generation cephalosporin increased from $13.0 \%$ in the past period to $40.9 \%$ in the recent period $(\mathrm{p}=0.026)$. In the case of fluoroquinolone, the change in antibiotic resistance was not significant from $26.1 \%$ in the past period to $27.3 \%$ in the 
recent period $(p>0.999)$. Aminoglycoside resistance increased from $4.3 \%$ in the past period to $6.8 \%$ in the recent period and carbapenem resistance decreased from $4.3 \%$ in the past period to $2.3 \%$ in the recent period. Changes of aminoglycoside and carbapenem resistances was not significant $(\mathrm{p}>0.999)$ (Table 2$)$.

\section{DISCUSSION}

Acute bacterial prostatitis is an acute infectious disease that occurs at the prostate site caused by pathogens. Ha et al. [2] and Cho et al. [8] reported E. coli, P. aeruginosa, and $K$. pneumoniae to be the major pathogens. On the other hand, Park et al. [9] reported a relatively low incidence of $P$. aeruginosa infection. In this study, similar results, on the major causative organisms to previous studies were observed, and additional species, such as $P$. mirabilis, $S$. aureus, and Streptococcus were observed in the recent period. No significant differences in the incidence of other studies of Korea were noted.

In 2011, the domestic guidelines for acute bacterial prostatitis were to choose between fluoroquinolone, thirdgeneration cephalosporin, or cephalosporin and aminoglycoside combination therapy. The guidelines for antibiotic use in 2018 were formulated to consider that the resistance of urinary tract infections to fluoroquinolone in Korea; the third-generation cephalosporin, extensive $\beta$-Lactam $/ \beta$-Lactamase inhibitor, and carbapenem were used as in-patient

Table 1. Differences between two periods of clinical manifestation in acute bacterial prostatitis patients

\begin{tabular}{|c|c|c|c|c|}
\hline Parameter & $\begin{array}{c}\text { Past period } \\
(2004-2007, n=50)\end{array}$ & $\begin{array}{c}\text { Recent period } \\
(2014-2017, n=72)\end{array}$ & Total $(n=122)$ & $\mathrm{p}$-value \\
\hline Mean age (y) & $55.5 \pm 13.2$ & $62.0 \pm 15.3$ & $59.3 \pm 14.8$ & 0.016 \\
\hline Hypertension & $12(24.0)$ & $26(36.1)$ & $38(31.1)$ & 0.421 \\
\hline Diabetes mellitus & $4(8.0)$ & $12(16.7)$ & $16(13.1)$ & 0.719 \\
\hline Cerebrovascular accident & $2(4.0)$ & $5(6.9)$ & $7(5.7)$ & 0.138 \\
\hline \multicolumn{5}{|l|}{ Infection route } \\
\hline Hospital & $1(2.0)$ & $4(5.6)$ & $5(4.1)$ & 0.406 \\
\hline Urologic manipulation & $1(2.0)^{\mathrm{a})}$ & $1(1.4)^{\mathrm{b})}$ & - & \\
\hline Prostate biopsy & $7(14.0)$ & $1(1.4)$ & $8(6.6)$ & 0.008 \\
\hline Hospitalization period $(\mathrm{d})$ & $7.9 \pm 4.2$ & $6.9 \pm 3.4$ & $7.3 \pm 3.8$ & 0.146 \\
\hline \multicolumn{5}{|l|}{ Intensive care unit treatment } \\
\hline Number & $5(10.0)$ & $7(9.7)$ & $12(9.8)$ & $>0.999$ \\
\hline Period (d) & $4.2 \pm 1.3$ & $4.1 \pm 1.4$ & $4.2 \pm 1.3$ & 0.943 \\
\hline
\end{tabular}

Values are presented as mean \pm standard deviation or number (\%).

-: not available.

${ }^{\text {a) Cystoscopy, }}{ }^{\text {b) }}$ transurethral resection of the prostate.

Table 2. Results of the detected microbial species and resistances

\begin{tabular}{|c|c|c|c|c|}
\hline Parameter & Past period (2004-2007) & Recent period (2014-2017) & Total & $\mathrm{p}$-value \\
\hline \multicolumn{5}{|l|}{ Species } \\
\hline No growth & 27 & 28 & 55 & \\
\hline Growth & 23 & 44 & 67 & \\
\hline Escherichia coli & $18(78.3)$ & $26(59.1)$ & $44(65.7)$ & 0.176 \\
\hline Klebsiella pneumoniae & $3(13.0)$ & $4(9.1)$ & $7(10.4)$ & 0.684 \\
\hline Pseudomonas aeruginosa & $1(4.3)$ & $2(4.5)$ & $3(4.5)$ & $>0.999$ \\
\hline Etc. $^{\text {a) }}$ & 0 & $9(20.5)$ & $9(13.4)$ & \\
\hline \multicolumn{5}{|l|}{ Resistance to antibiotics } \\
\hline Fluoroquinolones & $6(26.1)$ & $12(27.3)$ & $18(26.9)$ & $>0.999$ \\
\hline Aminoglycosides & $1(4.3)$ & $3(6.8)$ & $4(6.0)$ & $>0.999$ \\
\hline Third generation cephalosporins & $3(13.0)$ & $18(40.9)$ & $21(31.3)$ & 0.026 \\
\hline Carbapenems & $1(4.3)$ & $1(2.3)$ & $2(3.0)$ & $>0.999$ \\
\hline ESBL positive & $1(4.3)$ & $11(25.0)$ & 12 (17.9) & 0.045 \\
\hline
\end{tabular}

Values are presented as number only or number (\%).

ESBL: extended-spectrum beta lactamases.

${ }^{\text {a) }}$ Proteus mirabilis, Staphylococcus aureus, and Streptococcus. 
intra-venous antibiotics. After use, the patients were discharged and switched to oral antibiotics for 2 to 4 weeks when their symptoms improved $[2,10,11]$. In this study, however, the rate of resistance to third-generation cephalosporin increased from $13.0 \%$ in the past period to $40.9 \%$ in the recent period, whereas the change in antibiotic resistance of the fluoroquinolones was insignificant. These changes in antibiotic resistance to fluoroquinolone have been reported $[2,12]$, and antibiotic resistance has not increased significantly because fluoroquinolone has been used for a considerable period. Gashe et al. [13] reported $44.0 \%$ and $43.5 \%$ resistance rates of ceftriaxone and ceftazidime, respectively, in all specimens including urine cultures. Fluoroquinolone was well known in the studies by Charalabopoulos et al. [14] and Naber and Sorgel [15] in that its permeability to the prostate is superior to that of the cephalosporin-based drug, which is advantageous for the treatment of prostatitis. In the present study, the change in antibiotic resistance of the fluoroquinolone series from $26.1 \%$ in the past period to $27.3 \%$ in the recent period was insignificant. Considering this, the use of fluoroquinolone in the selection of empirical antibiotics should be considered positively at present [9]. ESBL positivity increased from one case to 11 cases, indicating a change in antibiotic resistance. This is an indication that the resistance to antibiotics is caused by an increase in repeated antibiotic exposure. The selection of empirical antibiotics in the initial treatment should be based on the factors related to antibiotic resistance, such as recent antibiotic use [16].

The guidelines for the use of antibiotics in this hospital are the intravenous administration of levofloxacin $500 \mathrm{mg}$ once daily (qd) and intravenous injection of optional isepamicin $400 \mathrm{mg}$ qd. Levofloxacin is changed to ceftriaxone $1 \mathrm{~g}$ twice a day if there is a history of quinolone antibiotics within the last 3 months, or if the patient is suspected of having renal insufficiency. In addition, if there are confirmed results of the previous culture tests, the antibiotic resistance is checked with reference to those results, and the empirical antibiotic is finally determined. Cultures should be examined before the antibiotics are used to analyze the antibiotic changes afterwards. At discharge, levofloxacin was replaced with oral medication. When ceftriaxone was used, it was replaced with a 3rd-generation cephalosporin oral antibiotic. The discharged patients were followed up for approximately one week.
When other antibiotics were used, oral medicines were prescribed according to the recently conducted culture test. If there was no oral medication, the period of hospitalization was extended and the patient was discharged after using the intravenous antibiotic for approximately one week.

After the prostate biopsy, bacterial prostatitis is more resistant to multiple organisms than community infections and is associated with a higher risk of sepsis [17]. Therefore, fluoroquinolone is used mainly in prophylactic antibiotics, but is recommended to be used immediately use after a rectal culture and prior to the biopsy because the antibiotic resistance of intestinal bacteria is likely to occur $[18,19]$.

The incidence of acute bacterial prostatitis after a prostate biopsy was reduced in this hospital, suggesting that the combination of fluoroquinolone and aminoglycoside was used prophylactically before the test and a prostate biopsy was then performed. Further research will be needed to verify this.

The mean age of the patients admitted to hospital with acute bacterial prostatitis increased while the number of hospital days decreased slightly. The increase in the mean age might have been influenced by the increase in the number of elderly patients because of the increasing average age. In addition, the decrease in the number of hospital days was not statistically significant, but the appropriate treatment guidelines may be studied and applied.

This study is based on the research data of one center due to the specialty of the hospital; the majority of the patient group work in the police force. On the other hand, due to the low specificity of the jobs of the police, the difference in the incidence of disease among the police population and the general population appears to be small.

The limitation of the study was the small number of samples by setting the period to four years each. The patterns of antibiotic use changed gradually, and the changes in antibiotic resistance caused by these changes appeared gradually. The difference was compared with the 10 year difference for each four year period because a significant change in antibiotic resistance was not observed when the study period was increased to supplement the small sample. In addition, this study was conducted based on the medical records of the hospitalized patients. Therefore, there was a part of the history of recent antibiotics use at the time of admission, because the reliability of the records was poor. Additional research that reinforces this will be needed. 


\section{CONCLUSIONS}

In this study, the mean age of hospitalized patients with acute bacterial prostatitis increased, while the number of hospital days decreased slightly. No significant change in resistance to fluoroquinolone was observed, but the resistance to third generation cephalosporin increased significantly. The proportion of ESBL-producing bacteria increased. Therefore, caution should be exercised when using antibiotics to treat acute prostatitis. Further research regarding this issue will be needed.

\section{CONFLICT OF INTEREST}

No potential conflict of interest relevant to this article was reported.

\section{AUTHOR CONTRIBUTIONS}

B.H.K. participated in data collection and wrote the manuscript. I.C.C. and K.C. participated in the study design and performed the statistical analysis. S.K.M. participated in the study design and coordination and helped to draft the manuscript. All authors read and approved the final manuscript.

\section{ORCID}

Byoung Hoon Kim, https://orcid.org/0000-0001-9470-8947 Kwibok Choi, https://orcid.org/0000-0003-3036-4959 In-Chang Cho, https://orcid.org/0000-0001-8906-3478 Seung Ki Min, https://orcid.org/0000-0002-9638-9668

\section{REFERENCES}

1. Yoon $\mathrm{BI}$, Han DS, Ha US, Lee SJ, Sohn DW, Kim HW, et al. Clinical courses following acute bacterial prostatitis. Prostate Int 2013;1:89-93.

2. Ha US, Kim ME, Kim CS, Shim BS, Han CH, Lee SD, et al. Acute bacterial prostatitis in Korea: clinical outcome, including symptoms, management, microbiology and course of disease. Int J Antimicrob Agents 2008;31 Suppl 1:S96-101.

3. Brede CM, Shoskes DA. The etiology and management of acute prostatitis. Nat Rev Urol 2011;8:207-12.

4. Sharp VJ, Takacs EB, Powell CR. Prostatitis: diagnosis and treatment. Am Fam Physician 2010;82:397-406.
5. Groen J, Pannek J, Castro Diaz D, Del Popolo G, Gross T, Hamid $\mathrm{R}$, et al. Summary of European Association of Urology (EAU) guidelines on neuro-urology. Eur Urol 2016;69:324-33.

6. Lipsky BA, Byren I, Hoey CT. Treatment of bacterial prostatitis. Clin Infect Dis 2010;50:1641-52.

7. Etienne M, Chavanet P, Sibert L, Michel F, Levesque H, Lorcerie $\mathrm{B}$, et al. Acute bacterial prostatitis: heterogeneity in diagnostic criteria and management. Retrospective multicentric analysis of 371 patients diagnosed with acute prostatitis. BMC Infect Dis 2008;8:12.

8. Cho IR, Lee KC, Lee SE, Jeon JS, Park SS, Sung LH, et al. Clinical outcome of acute bacterial prostatitis, a multicenter study. Korean J Urol 2005;46:1034-9.

9. Park MG, Cho MC, Cho SY, Lee JW. Clinical and microbiological features and factors associated with fluoroquinolone resistance in men with community-acquired acute bacterial prostatitis. Urol Int 2016;96:443-8.

10. Wie SH, Kim BN, Kim JE, Park DW, Kang Cl, Lee HY, et al. Guideline for the antibiotic use in urinary tract infections. Cheongju: Korea Centers for Disease Control \& Prevention; 2018.

11. The Korean Society of Infectious Diseases, The Korean Society for Chemotherapy, Korean Association of Urogenital Tract Infection and Inflammation, The Korean Society of Clinical Microbiology. Clinical guideline for the diagnosis and treatment of urinary tract infections: asymptomatic bacteriuria, uncomplicated \& complicated urinary tract infections, bacterial prostatitis. Infect Chemother 2011;43:1-25.

12. Lee SJ, Lee DH, Park YY, Shim BS. A comparative study of clinical symptoms and treatment outcomes of acute bacterial prostatitis according to urine culture. Korean J Urol 2011; 52:119-23.

13. Gashe F, Mulisa E, Mekonnen M, Zeleke G. Antimicrobial resistance profile of different clinical isolates against thirdgeneration cephalosporins. J Pharm (Cairo) 2018;2018:5070742.

14. Charalabopoulos K, Karachalios G, Baltogiannis D, Charalabopoulos A, Giannakopoulos X, Sofikitis N. Penetration of antimicrobial agents into the prostate. Chemotherapy 2003;49: 269-79.

15. Naber KG, Sorgel F. Antibiotic therapy--rationale and evidence for optimal drug concentrations in prostatic and seminal fluid and in prostatic tissue. Andrologia 2003;35:331-5.

16. Lee $\mathrm{Y}$, Lee DG, Lee $\mathrm{SH}$, Yoo $\mathrm{KH}$. Risk factor analysis of ciprofloxacin-resistant and extended spectrum beta-lactamases pathogen-induced acute bacterial prostatitis in Korea. J Korean Med Sci 2016;31:1808-13.

17. Kim JW, Oh MM, Bae JH, Kang SH, Park HS, Moon du G. Clinical and microbiological characteristics of spontaneous acute prostatitis and transrectal prostate biopsy-related acute prostatitis: is transrectal prostate biopsy-related acute prostatitis a distinct acute prostatitis category? J Infect Chemother 2015;21:434-7. 
18. Lee SJ. Infection after transrectal ultrasound-guided prostate biopsy. Korean J Urol 2015;56:346-50.

19. Togo Y, Kubo T, Taoka R, Hiyama Y, Uehara T, Hashimoto J, et al. Occurrence of infection following prostate biopsy procedures in Japan: Japanese Research Group for Urinary Tract Infection (JRGU) - a multi-center retrospective study. J Infect Chemother 2014;20:232-7. 